\title{
Spatial Tuning Curves Along the Chick Basilar Papilla in Normal and Sound-Exposed Ears
}

\author{
J. Lifshitz, ${ }^{1}$ A. C. Furman, ${ }^{2}$ K. W. Altman, ${ }^{3}$ and J. C. Saunders ${ }^{2}$ \\ ${ }^{1}$ Department of Neurosurgery, University of Pennsylvania, Philadelphia, PA 19104, USA \\ ${ }^{2}$ Department of Otorhinolaryngology: Head and Neck Surgery, University of Pennsylvania, Philadelphia, PA 19104, USA \\ ${ }^{3}$ Department of Otolaryngology, Northwestern University, Chicago, IL 60611, USA
}

Received: 2 July 2002; Accepted: 15 December 2003; Online publication: 4 May 2004

\begin{abstract}
Intense sound exposure destroys chick short hair cells and damages the tectorial membrane. Within a few days postexposure, signs of repair appear resulting in nearly complete structural recovery of the inner ear. Tectorial membrane repair, however, is incomplete, leaving a permanent defect on the sensory surface. The consequences of this defect on cochlear function, and particularly frequency analysis, are unclear. The present study organizes the sound-induced discharge activity of cochlear nerve units to describe the distribution of neural activity along the tonotopic axis of the basilar papilla. The distribution of this activity is compared in 12-day postexposed and age-matched control groups. Spontaneous activity, tuning curves, and rate-intensity functions were measured in each unit. Discharge activity at 60 frequency and intensity combinations was identified in the tuning curves of hundreds of units. Activity at each of these criterion frequency/intensity combinations was plotted against the unit's characteristic frequency to construct spatial tuning curves (STCs). The STCs depict tone-driven cochlear nerve activity along the length of the papilla. Tuning sharpness, low- and high- frequency slopes, and the maximum response were quantified for each STC. The sharpness of tuning increased with increasing criterion frequency. However, within a frequency, increasing sound intensity yielded more broadly tuned STCs. Also, the high-frequency slope
\end{abstract}

Correspondence to: J. C. Saunders - University of Pennsylvania 5 Ravdin - ORL • 3400 Spruce Street - Philadelphia, PA - Telephone: (215) 898-7504; Fax: (215) 898-7504; email: saunderj@mail.med. upenn.edu was consistently steeper than the low-frequency slope. The STCs of exposed ears exhibited slightly less frequency selectivity than control ears across all frequencies and larger maximum responses for STCs with criterion frequencies spanning the tectorial membrane defect. When rate-intensity types were segregated, differences were observed in the STCs between saturating and sloping-up units. We propose that STC shape may be determined by global mechanical events, as well as localized tuning and nonlinear processes associated with individual hair cells. The results indicated that 12 days after intense sound exposure, global and local contributions to spatially distributed neural activity are restored.

Keywords: cochlear nerve, single nerve units, chicks, acoustic overstimulation, hair cell regeneration, tuning curves, basilar papilla

\section{INTRODUCTION}

Several mechanisms contribute to frequency selectivity in the avian inner ear. The first is a traveling wave along the basilar membrane. The properties of this traveling wave have been measured in pigeon and chicken and appear to be broadly tuned, exhibiting linear growth with stimulus intensity (von Békésy 1960; Gummer et al. 1987; Richter 2001). In addition, the hair cell membrane is tuned by a unique distribution of voltage-gated $\mathrm{Ca}^{2+}$ channels and $\mathrm{Ca}^{2+}$-gated $\mathrm{K}^{+}$channels (Fuchs et al. 1988). When the hair cell resonant frequency matches the frequency of the mechanical input to the hair bundle, the activity in 
attached cochlear nerves should show their greatest sensitivity and frequency selectivity.

The present study is driven by the observation of damage to the auditory sensory epithelium (the basilar papilla) with accompanying physiological changes following intense sound exposure. The nature of the structural and functional damage has been summarized elsewhere (Cotanche 1999; Smolders 1999).

When the sound-exposed chick ear is examined 12-14 days postexposure, remarkable structural recovery is evident (see Cotanche 1999). Despite impressive structural recovery, there remains a substantial physical defect on the papilla surface. The tectorial membrane over the acoustically induced lesion has healed incompletely. The lower honeycomb matrix regenerates, but the upper fibrous layer fails to return (Cotanche 1987; Adler and Saunders 1995). A scanning electron micrograph montage of this defect, obtained from a 15-day-old chick allowed to recover 12 days after being exposed to a $120 \mathrm{~dB}$ SPL $0.9 \mathrm{kHz}$ tone from 1 to 3 days of age, is seen in Figure 1 .

Physiologic manifestations of the defect in the 12day recovered chick ear have yielded surprisingly little. Chick single-unit recordings (from the cochlear nerve or nucleus magnocellularis) showed complete recovery of threshold shifts, spontaneous activity, and tuning curve frequency selectivity (Cohen and Saunders 1995; Saunders et al. 1996; Plontke et al. 1999). This recovery of function was clearly evident in the responses of units with characteristic frequencies (CFs) originating from hair cells that should occupy the frequency region of the papilla containing the defect (e.g., $0.7-1.4 \mathrm{kHz}$ ). Also, the endocochlear potential responses returned to normal in these young recovered ears (Poje et al. 1995). Additional evidence from labeled cochlear nerve units suggested that the exposure did not alter the tonotopic organization of nerve fibers along the papilla length (Chen et al. 1994, 1996b). Nevertheless, Plontke et al. (1999) showed abnormal rate-intensity functions in 12-day recovered cochlear nerve units, with CFs corresponding to frequencies subtended by the region of the lesion. The abnormal units exhibited steeper slopes and larger maximum responses at the highest intensity, despite the complete recovery of CF thresholds, spontaneous activity, and tuning curve selectivity. These authors suggested that abnormal rate-intensity behavior might arise from altered mechanical input to the hair cell sensory hair bundle, an intrinsic change in the transduction process, or alterations in the synaptic mechanisms of individual hair cells.

The present study examines frequency selectivity by measuring tone-stimulated cochlear nerve activity along the tonotopic axis of the basilar papilla. The

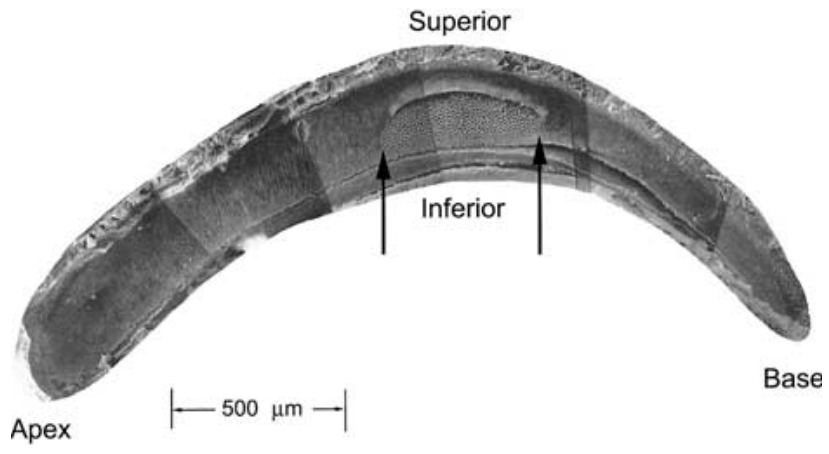

FIG. 1. A montage of scanning electron micrographs shows the papilla surface of an exposed (15-day-old) chick 12 days following intense sound exposure. The tectorial membrane is otherwise intact except over the site of the original lesion. The "honeycomb" (between arrows) of the lower tectorial membrane is seen within the boundaries of the lesion. For reference, the length of the lesion area is $460 \mu \mathrm{m}$.

spatial distribution of neural activity is used to determine whether the tectorial membrane lesion alters this aspect of frequency analysis.

The activity of hundreds of units was organized into spatial tuning curves (STCs), each constructed for a specific stimulus frequency and intensity combination (called the criterion frequency and intensity). The STCs provided a cochlear nerve proxy for frequency analytic processes along the length of the papilla. Spatially distributed patterns of neural activity have been reported across the sensory sheet of the cat organ of Corti (Kim and Molnar 1979; Shofner and Sachs 1986; Delgutte 1990; Kim et al. 1990). The same patterns have been described in crocodilian (caiman) and avian (starling) ears, which are the only nonmammalian inner ears that exhibit a basilar membrane traveling wave (Smolders and Klinke 1986; Gleich 1994). In this article various parameters of STCs were examined from the ears of age-matched control and sound-exposed but recovered chicks. We report that the shapes and parameters of STCs in exposed ears suggest that the process of frequency selectivity along the chick basilar papilla was minimally influenced by the tectorial membrane damage.

\section{METHODS}

\section{Animals and sound exposure}

White leghorn chicks (Gallus domesticus) were divided into a control group and an exposed group when one day old. The exposed group was overstimulated with a $0.9-\mathrm{kHz}$ pure tone at $120 \mathrm{~dB}$ SPL for 48 hours between 1 and 3 days of age. The exposed animals were allowed to recover for approximately 12 days (range of 11-13 days). Sound exposure was carried out in a sound-attenuated booth, where the chicks were sus- 
pended in a wire mesh cage beneath a 30 -cm-diameter speaker. Second and third harmonics were at least $45 \mathrm{~dB}$ below the fundamental. The stimulus intensity was calibrated with a 12.5 -mm condenser microphone and expressed as $\mathrm{dB}$ SPL relative to $20 \mu \mathrm{Pa}$. Variability in the sound field was $\pm 1.0 \mathrm{~dB}$. Details of the exposure conditions can be found elsewhere (Saunders et al. 1996). All measures of cochlear nerve activity occurred when the chicks were between 14 and 16 days of age, and, for each exposed animal examined, an age-matched control chick was tested.

\section{Animal preparation}

Each chick was anesthetized with an intramuscular injection of a $25 \%$ ethyl carbamate solution (Urethane) at a dose of $0.01 \mathrm{ml} / \mathrm{g}$. A tracheotomy was performed, and the left ear canal was removed to expose the tympanic membrane. The skull was exposed and secured to a head holder with cyanoacrylate glue and dental cement. A 5.0-mm-diameter hole, opened through the outer layer of the temporal bone, allowed access to the inner bony layer of the skull over the cochlear capsule. The recessus scala tympani was then exposed by cutting a 1.5 -mm-diameter hole in the bone over the cochlear capsule. The capsule was pierced and expanded to the limits of the access hole. The cochlear ganglion was seen as a "white band" on the distal wall of scala tympani.

Treatment and care of chicks in this study followed procedures approved by the Institutional Animal Care and Use Committee of the University of Pennsylvania.

\section{Cochlear nerve recordings}

Borosilicate glass microelectrodes (15-30 $\mathrm{M} \Omega$ ) filled with $3 \mathrm{M} \mathrm{KCl}$ were attached to a microdriver and lowered into the scala tympani. Signals detected by the electrode were amplified and sent to an oscilloscope, audio monitor, and level detector. The squarewave pulse from the level detector was linked to computer software that counted the intervals between pulses with 0.1 -ms resolution.

When a unit was encountered, data collection began with a 6.0-s sample of spontaneous activity, expressed as spikes per second (S/s). The tuning curve of the unit was determined next. An array of 1540 tone bursts (40-ms duration, 5-ms rise/decay time, 9 / $\mathrm{s}$ repetition rate) was randomly presented once at each of 55 frequencies between 0.1 and $4.0 \mathrm{kHz}$ and at 28 intensities in $3.33 \mathrm{~dB}$ steps between 10 and 100 $\mathrm{dB}$ SPL. The resulting spectral response plots were processed to produce tuning curves like those in Figure 2. The importance of these tuning curves is that unit discharge activity can be identified

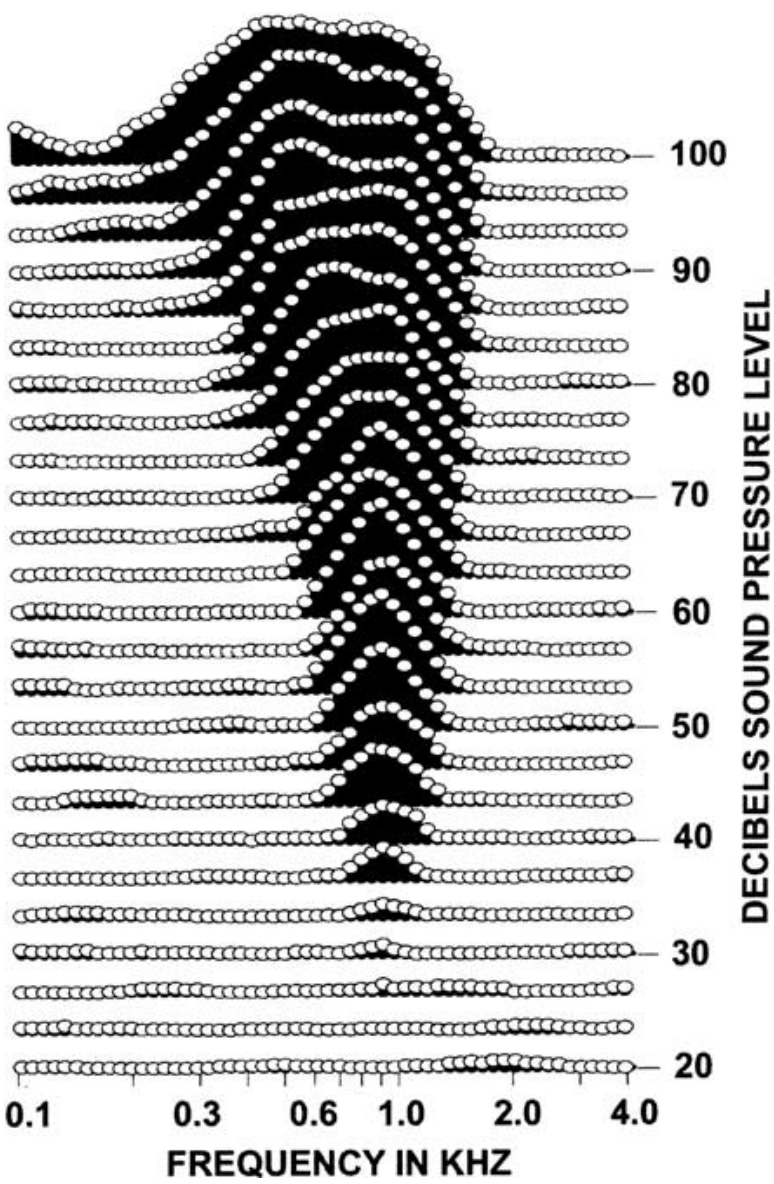

FIG. 2. An example of a spectral response plot tuning curve is presented. Discharge activity can be determined in this plot for any criterion frequency and intensity level combination.

throughout the entire range of sampled auditory space. This is essential in constructing the STCs. From these tuning curves the $\mathrm{CF}$ and $\mathrm{CF}$ threshold were determined (e.g., $0.92 \mathrm{kHz}$ and $27 \mathrm{~dB}$ in Fig. 2). Next, a rate-intensity function, describing the relation between stimulus SPL and S/s, was determined at the CF. A subjective decision categorizing a unit as either a saturating, sloping-up, or straight rate-intensity (RI) type was based on a visual examination of the function (see Saunders et al. 2002 for details).

\section{Construction of the spatial tuning curves}

STCs were constructed and analyzed at ten (10) equally spaced criterion frequencies between 0.34 and $2.16 \mathrm{kHz}$. At each criterion frequency, discharge activity was examined at 40,50,60, 70, 80, and $87 \mathrm{~dB}$ SPL. The discharge response data in the raw spectral response plots were noisy due to the single stimulus presentation at each frequency/intensity combination. However, noise was reduced at each criterion frequency/intensity combination by averaging discharges across adjacent intensities and within fre- 


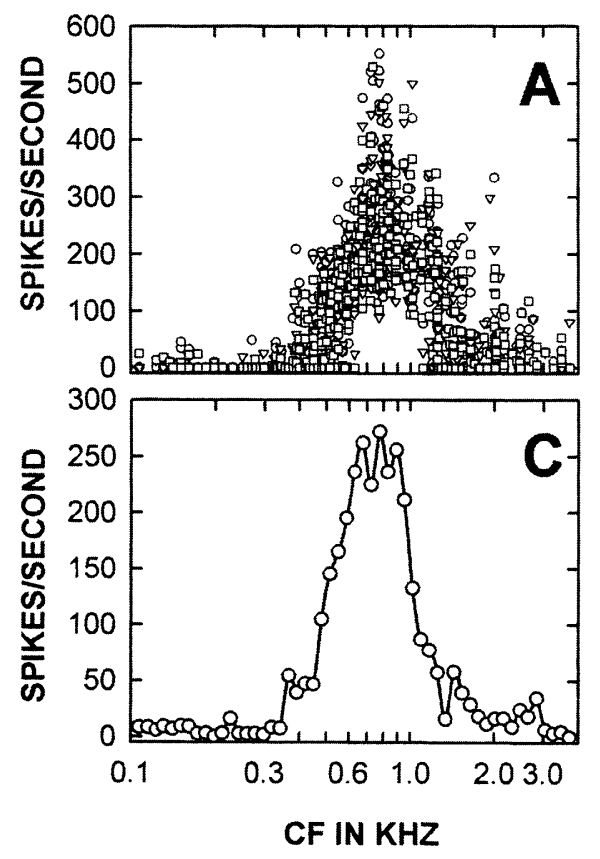

quency bins. Figure 3 illustrates the steps for constructing an $80 \mathrm{~dB}$ STC at $0.78 \mathrm{kHz}$. The level of discharge activity in spikes per second $(\mathrm{S} / \mathrm{s})$ at $0.78 \mathrm{kHz}$ for $76.6,80.0$ and $83.3 \mathrm{~dB}$ SPL was first identified in tuning curves of 458 control units. The levels of discharge activity were then plotted against the CF of each unit (Fig. 3A), and activity was then averaged over the three intensity levels (Fig. 3B). The results were further averaged over all units contained within each of 53 successive frequency bins (beginning at 0.11 and ending at $3.72 \mathrm{kHz}$, see Fig. 3C). Finally, the data were subject to a three-point running average to more clearly represent the curve (Fig. 3D). The vertical bars in Figure 3D represent the variability (+1.0 standard error of the mean), which was representative of all the STCs examined.

The maximum discharge rates at the criterion frequency (in $\mathrm{S} / \mathrm{s}$ ), the slope on the high and lowfrequency sides of the curve (in S/s/octave), and the $Q$ ratio at the $20 \%$ and $50 \%$ levels of discharge activity were measured in each of the 60 STCs. Slope was determined by identifying the data point closest to an activity level halfway between the peak response of the STC and the noise level of the curve (on both the high-and the low-frequency sides of the function). A regression line was then fit to the data points, above and below the midpoint, that exhibited linear changes in discharge activity. The slopes of the regression lines for these skirts were expressed as $\mathrm{S} / \mathrm{s}$ / octave, with the center frequency of the octave defined by the "midpoint" frequency (see insert on Fig. 9B).

The $Q$ ratio was determined by measuring the magnitude (in $\mathrm{S} / \mathrm{s}$ ) between the discharge activity level at the criterion frequency of the STC and the noise floor (defined by the average spontaneous activity of the sample). The $Q$ ratios were calculated at two levels of discharge activity: one at $20 \%$ and the other at $50 \%$ of the distance between the discharge activity at the criterion frequency and that at the noise floor (see Fig. 3D). At each of these levels, the high and low-frequency intercepts on the STC were determined. The low-frequency intercept was subtracted from the high-frequency intercept to determine the bandwidth (in $\mathrm{kHz}$ ). Dividing the bandwidth by the criterion frequency yielded the $Q$ ratio. Larger $Q$ ratios represent a function with greater frequency selectivity. Since the $Q$ ratio is normalized by the criterion frequency, it can be used to directly compare frequency selectivity across STCs of different frequencies.

These quantitative evaluations of the STCs were compared at the different criterion frequency and intensity combinations, between age-matched control and 12-day recovered units. Finally, STCs were constructed from those units exhibiting either the saturating or sloping-up RI types, and these were evaluated using the same slope and frequency selectivity methods described above.

As a last point we note the occurrence of "dropouts." The tuning curves were based on activity elicited by a single tone burst at each frequency/intensity combination. There were instances when a "dropout" occurred in the tuning curve matrix, arising from a sudden reduction in discharge amplitude, most likely from momentary electrode movement due to a breathing artifact. Whenever a zero discharge value was encountered in the sound-driven 

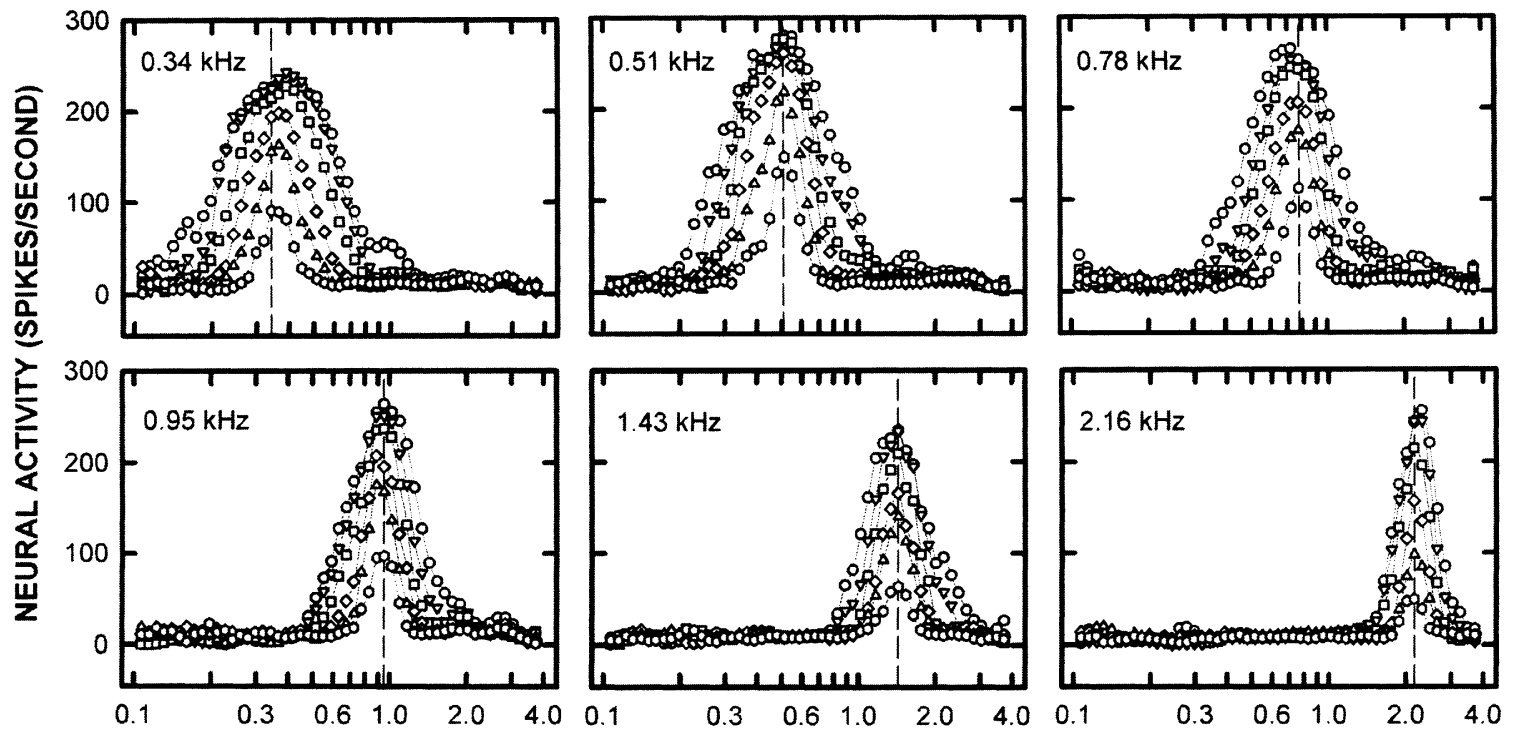

CHARACTERISTIC FREQUENCY (KHZ)

FIG. 4. Control STCs at 6 criterion frequencies are illustrated. The parameter within each panel is the criterion intensity at each of six levels. The vertical dashed line shows the criterion frequency. These curves were constructed from a sample of 458 units. Each symbol represents the following criterion intensities: $(\bigcirc) 87 \mathrm{~dB},(\nabla) 80 \mathrm{~dB},(\square) 70 \mathrm{~dB},(\diamond) 60 \mathrm{~dB},(\Delta) 50 \mathrm{~dB},(\bigcirc) 40 \mathrm{~dB}$

area, a compensation procedure was introduced. Activity in the adjacent higher and lower frequencies about the dropout was averaged, and the resulting value substituted for the zero level of discharge activity at the dropout frequency. In this way, the integrity of the tuning curve was maintained. In over 1.4 million tone bursts sampled in the 913 tuning curves examined here, this procedure was introduced in less than $10 \%$ of those stimulus conditions residing within the sound-driven area of the tuning curve.

\section{RESULTS}

\section{General observations}

We report data from 458 control and 455 exposed units whose $\mathrm{CF}$ thresholds were no greater than approximately $20 \mathrm{~dB}$ above the lowest $\mathrm{CF}$ threshold detected across frequency. In order to sample STCs over a wide range of sound intensities, it was necessary to conduct the analysis on units with tuning curves having the lowest CF thresholds. Lower threshold units provided the widest sound-driven dynamic range, and this facilitated construction of the STCs. For example, a unit with a $51 \mathrm{~dB}$ SPL CF threshold would contribute only spontaneous activity to those STCs at 40 and $50 \mathrm{~dB}$ SPL. Approximately 150 additional units in each group were discarded because the threshold level at the CF exceeded the 20-dB cutoff. All units contributing to the STCs with
CFs between 0.2 and $2.4 \mathrm{kHz}$ had $\mathrm{CF}$ thresholds that were $38 \mathrm{~dB}$ SPL or less.

\section{Control and exposed STCs}

Figure 4 shows six STCs constructed from units in the control group. The parameters within each panel are the six intensity levels. The vertical dashed lines in each panel indicate the criterion frequency. Several observations can be drawn from these data. Neural activity systematically decays on the high- and lowfrequency skirts of the STCs. In almost all cases, the frequency at the peak of discharge activity is the same as the criterion frequency. Also, the bandwidth of the STC becomes narrower on the logarithmic frequency axis, as the criterion frequency increases. Close examination of the curves further reveals that there is a compression of the response magnitude as the stimulus level increases. Moreover, the level of compression is independent of frequency. Finally, the STCs increase in bandwidth as the criterion intensity increases, and the decline in discharge activity on the high- and low-frequency skirts is slightly asymmetrical.

Figure 5 illustrates the STC curves obtained from exposed animals allowed 12 days of recovery. The dashed vertical line again represents the criterion frequency, while the solid vertical line indicates the exposure frequency $(0.9 \mathrm{kHz})$. All of the characteristics described for Figure 4 apply to the plots in Figure 5. A visual examination of Figures 4 and 5 suggest subtle differences between the STCs in these 

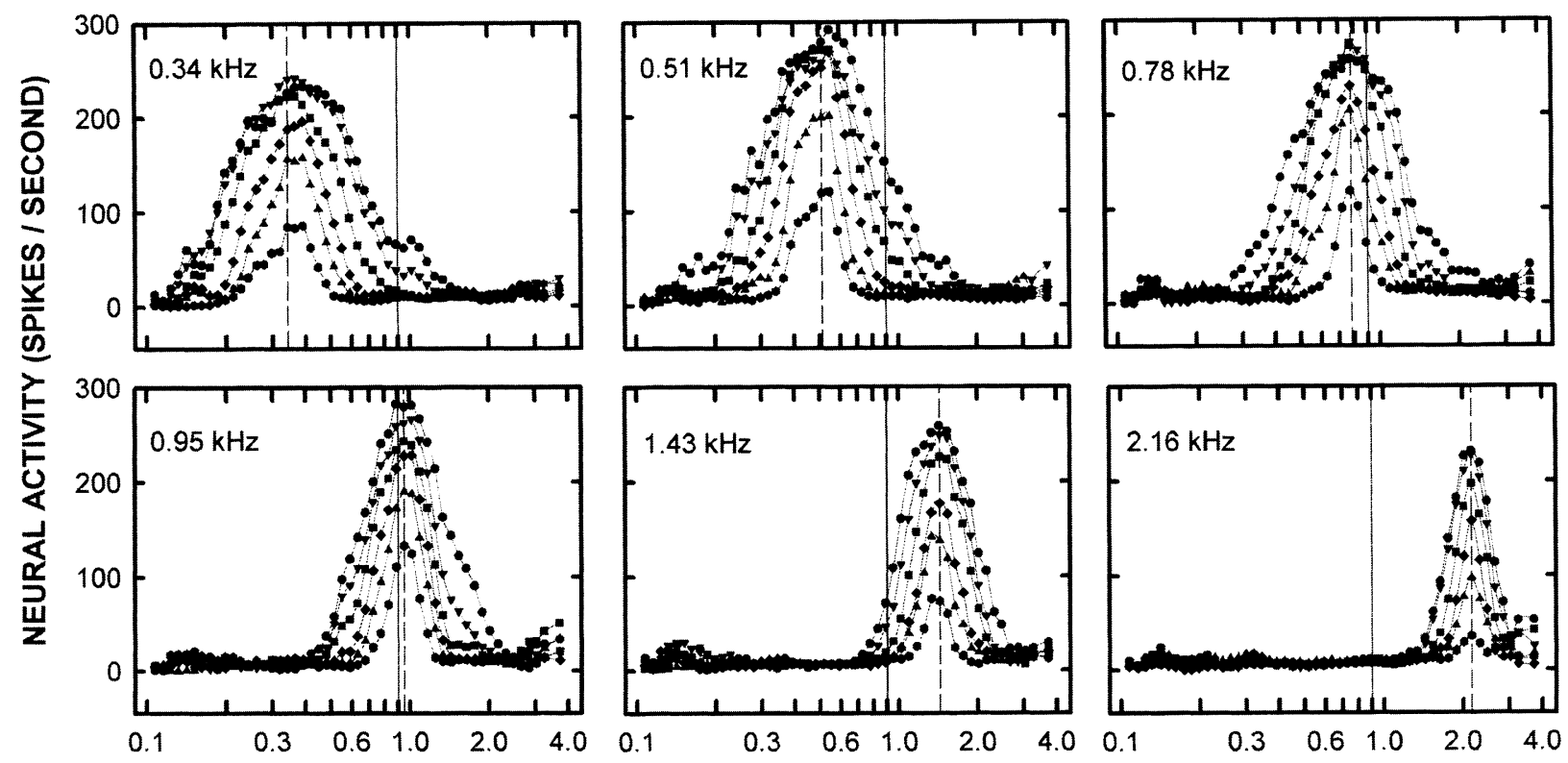

CHARACTERISTIC FREQUENCY (KHZ)

FIGURE 5. STCs in exposed ears are illustrated. The parameter in each panel is intensity level and the vertical dashed line is the criterion frequency. The solid vertical line provides a reference for the $0.9-\mathrm{kHz}$ exposure frequency. These curves were constructed from a sample of 455 units. Each symbol represents the following criterion intensities: $(\bullet) 87 \mathrm{~dB},(\boldsymbol{\nabla}) 80 \mathrm{~dB},(\boldsymbol{\square}) 70 \mathrm{~dB},(\boldsymbol{\bullet}) 60 \mathrm{~dB},(\boldsymbol{\Delta}) 50 \mathrm{~dB},(\boldsymbol{)}) 40 \mathrm{~dB}$.

two groups. The remainder of the results quantitatively evaluates the STCs between the two groups.

\section{The criterion frequency maximum response}

Figure $6 \mathrm{~A}, \mathrm{~B}$ shows the maximum response (at the criterion frequency) for each STC at all six intensity levels for the two groups. The criterion frequency was the same as the frequency of the maximum response in 47/60 and 39/60 STCs in the control and exposed groups, respectively. A systematic pattern of deviation could not be identified in those curves where the frequency of the maximum response was other than the criterion frequency (see Figs. 4 and 5).

Figure 6A,B reveals the compressive nonlinearity in which the three highest intensities collapse together or overlap each other. Figure $6 \mathrm{C}$ averages the peak responses over all intensities, and a systematic increase is seen in the peak response of the STCs in exposed animals between 0.78 and $1.43 \mathrm{kHz}$. Paired comparison tests, using the pooled error term from a two-way analysis of variance (ANOVA), revealed that the maximum discharge rate was significantly greater in exposed units for STCs at $0.78,0.95$, and $1.17 \mathrm{kHz}$ $(p<0.05)$.

Figure 7 shows rate-level functions, at three STC frequencies, derived from the results in Figure 6A,B. The level of spontaneous activity is depicted (arbitrarily plotted at $5 \mathrm{~dB}$ SPL and at the CF threshold averaged across the sample of cells). The discharge activity in the STCs was also determined at $5 \mathrm{~dB}$ above the STC threshold. The remaining seven data points were obtained directly from Figure 6A,B. The STCs from exposed ears have a higher maximum response and tend to grow with a somewhat steeper slope. At lower and higher criterion frequencies these rate-level functions were much the same in both the control and exposed groups (data not shown).

\section{Frequency selectivity of the STCs}

Figure 8 shows the $Q$ ratios across criterion frequency at the $20 \%$ and $50 \%$ levels. Data were averaged over the 40 and $50 \mathrm{~dB}$ (Fig. 8A, B) and the 80 and $87 \mathrm{~dB}$ (Fig. 8C, D) criterion intensities. At both levels the sharpness of tuning increases as criterion frequency increases. The $Q$ values at the $50 \%$ level are expectedly smaller than at the $20 \%$ level because of the increased bandwidth. Furthermore, at higher intensity levels the $Q$ values were substantially smaller. With two exceptions $(2.16 \mathrm{kHz}$ in panel A and $1.43 \mathrm{kHz}$ in panel $B$ ), the $Q$ values of exposed units showed consistently poorer frequency selectivity (smaller $Q$ values) than in control units. The results at 60 and 70 dB SPL were similar (data not shown). It was not possible to provide an indication of variability in Figure 8 because the data were derived from the synthesized STCs in Figures 4 and 5. 

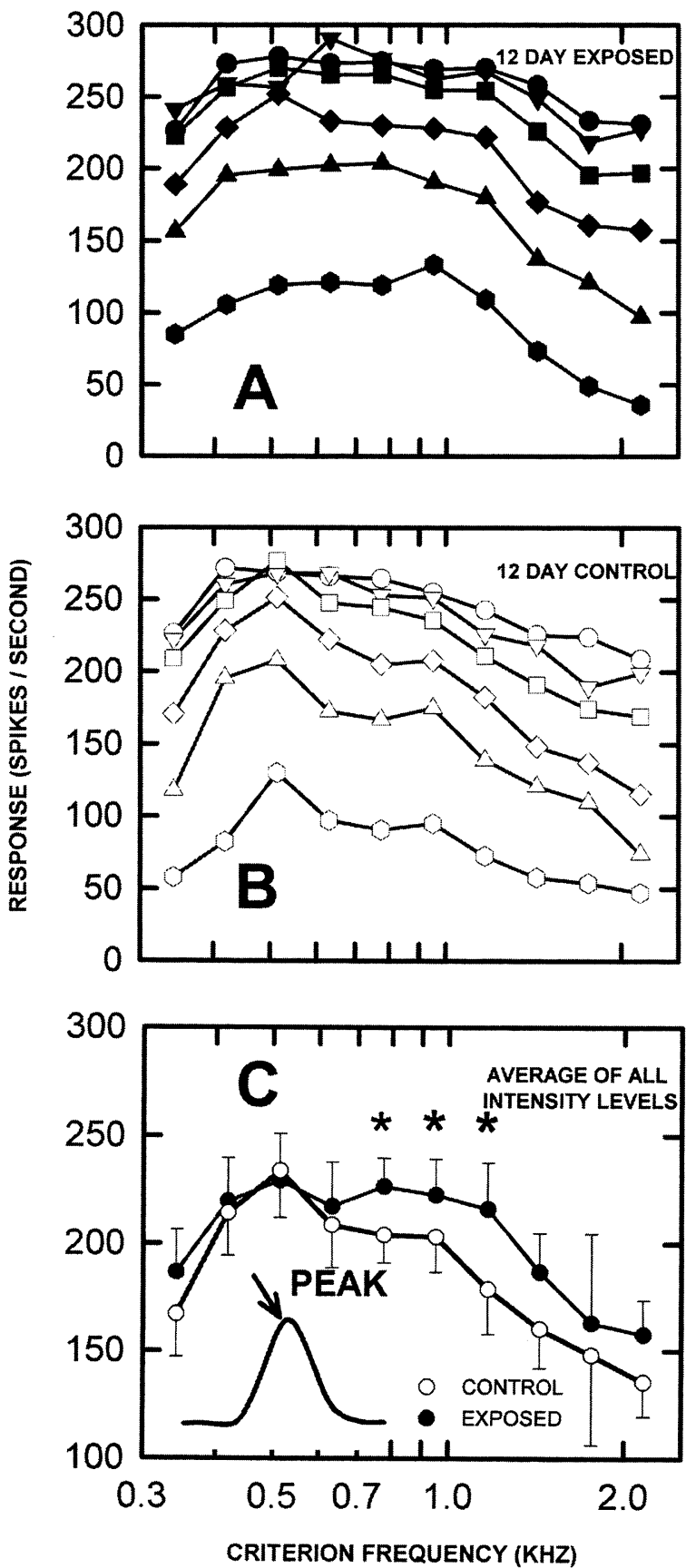

FIG. 6. The maximum response at the criterion frequency for STCs in control (A) and exposed (B) ears. C Average of the maximum responses over all intensities. The insert depicts the location of maximum response at criterion frequency for an individual STC. The vertical bars represent 1 standard error of the mean and those points with an asterisk $\left(^{*}\right)$ exhibit a significant difference between control and exposed conditions $(p<0.05)$. Symbols in $\mathbf{A}$ and $\mathbf{B}$ indicate the following intensities: $(\bigcirc) 87 \mathrm{~dB},(\nabla) 80 \mathrm{~dB},(\square) 70 \mathrm{~dB},(\diamond) 60 \mathrm{~dB}$,

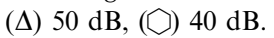

\section{High- and low-frequency slopes}

The STCs in Figures 4 and 5 appear to have steeper skirts as criterion frequency increases, but this can be deceptive because of the logarithmic frequency axis in these plots. To compensate for the log axis, slope can be described as a change in discharge activity over a frequency interval defined by a fixed ratio of a center frequency. This is the so-called "rolloff" which was derived for both the high- and low-frequency STC skirts and expressed as S/s/octave. The frequency at the midpoint of the skirt for each STC function served as the reference, and using several data points above and below the reference, a linear regression was fit to the skirt. The slope of the regression (expressed as $\mathrm{S} / \mathrm{s} / \mathrm{Hz}$ ) was then converted to discharge activity occurring over a 1-octave bandwidth about the midpoint frequency.

The results in Figure 9A show the slopes on the high- and low-frequency skirts in both control and exposed groups. These data were obtained by averaging the curves at 60,70 , and $80 \mathrm{~dB}$ SPL. There are three features in these data. The high- and low-frequency skirts of the STCs show an orderly increase in rolloff (meaning that the slopes are getting steeper) with increasing criterion frequency. Furthermore, the rolloff was the same between control and exposed STCs, on both the high- and the low-frequency skirt. Finally, the high-frequency slope, when collapsed across exposed and control conditions over all frequencies, was 1.39 times steeper than the low-frequency slope. Interestingly, the high- and lowfrequency rolloffs in the basilar membrane response of the pigeon were 20 and $14 \mathrm{~dB} /$ octave, respectively (Gummer et al. 1987). The ratio of this difference was 1.42.

The appropriateness of the regression lines on which the slopes were determined is confirmed in Figure 9B. The high- and low-frequency regression lines were extended above the STC until they intercepted each other, and in this way the intercept frequency was determined. Although the slopes of the high- and low-frequency skirts were slightly different, this difference was small, and the intercept frequency over all 120 control and exposed STCs was nearly identical to the criterion frequency. This is seen in Figure 9B where the intercept frequencies of the regression lines are plotted against criterion frequency. The regression line has a slope of $1.0\left(r^{2}=0.99\right)$.

\section{STC and RI function}

This subsection seeks to determine if saturating or sloping-up RI types uniquely contribute to the shape of the STCs observed here. Four RI types are seen in the chick cochlear nerve and are called saturating, sloping-up, sloping-down, and straight (Saunders et al. 2002). Small numbers of sloping-down or straight units were observed. However, both types were excluded from the present analysis because their numbers were too small to produce well-defined STCs. In 


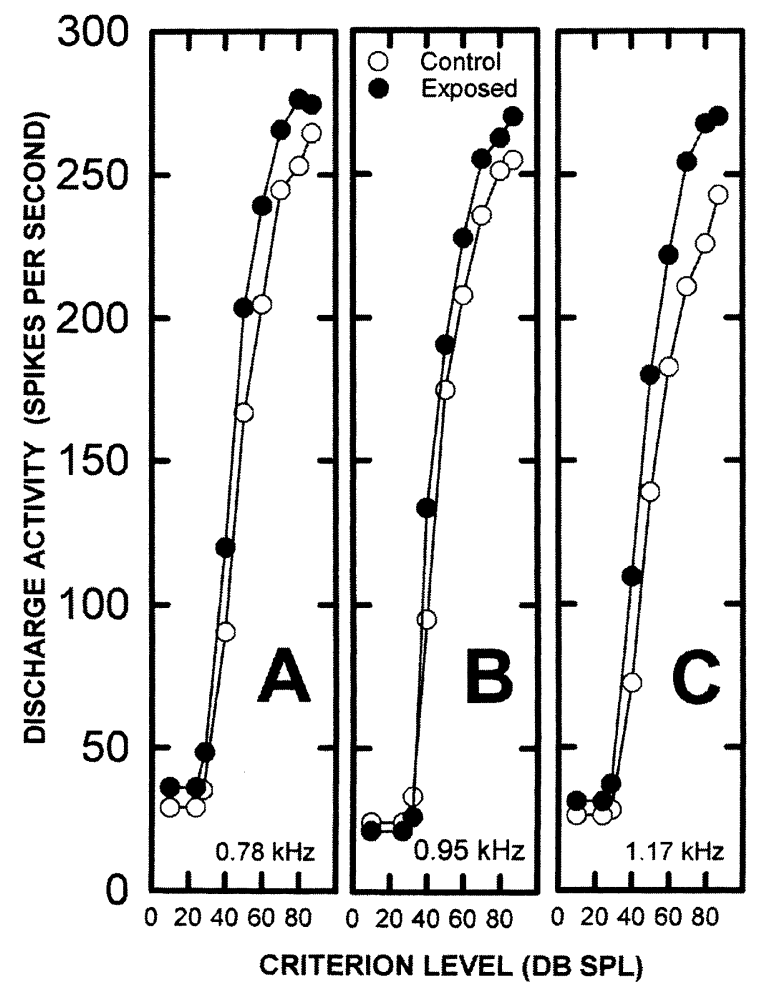

FIG. 7. The criterion frequency maximum responses, as well as two additional points, are plotted against stimulus level at three frequencies. The parameter in each panel is the control and exposed ear. The additional points represent discharge activity approximately $5 \mathrm{~dB}$ above threshold, as well as the level of spontaneous activity.

the sample of control units, 255 (55.7\%), 154 $(33.5 \%)$, and $49(10.7 \%)$ of the units were, respectively, saturating, sloping-up, and straight RI types. In the exposed sample, these numbers were 236 (51.9\%), $184(40.5)$, and $34(7.5 \%)$, respectively.

Figure 10A,B show the STCs at $0.95 \mathrm{kHz}$ for control and exposed saturating RI units, and the ratelevel function for these data appear in the insert of Figure10B. The control and exposed rate-level functions show curves nearly identical to each other. The saturation of the response begins around $70 \mathrm{~dB}$ SPL. The exposed curves, particularly for levels $60 \mathrm{~dB}$ or higher, appear to be more broadly tuned than the control STCs. This was examined more closely by determining the $Q$ values for the $20 \%$ and $50 \%$ levels of discharge activity (see Fig. 11A,B), and, as can be seen, the STCs in exposed chicks were more broadly tuned (have lower $Q$ ratios) than the control curves at all criterion intensities.

Figure 10C,D shows the STCs at $0.95 \mathrm{kHz}$ for control and exposed sloping-up RI units. The insert in Figure 10D represents the rate-level function at $0.95 \mathrm{kHz}$. The STCs in exposed chicks rise to a higher level and have slightly steeper slopes than the control function, and the exposed units at $87 \mathrm{~dB}$ SPL show an $18.8 \%$ larger discharge level than the controls. It is

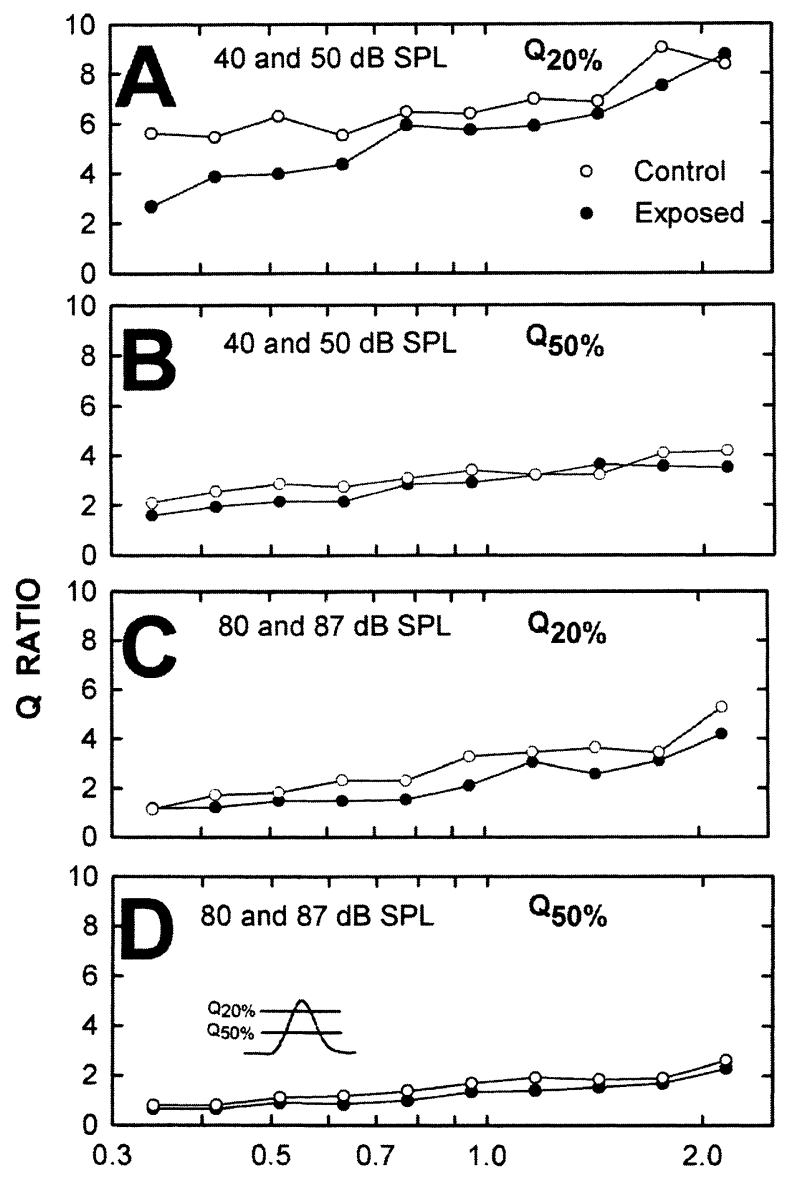

CRITERION FREQUENCY (KHZ)

FIG. 8. Frequency selectivity (Q ratio) in control and exposed STCs are shown for the 20 and 50 levels of activity. A,B The results for STC at the 40 and $50 \mathrm{~dB}$ criteria; C,D results for STC at the 80 and $87 \mathrm{~dB}$ criteria. Insert in D shows from which part of each STC these calculations were derived.

also obvious that the peak levels of activity in the sloping-up types are higher than the saturating RI types. The $Q$ values for the $20 \%$ and $50 \%$ levels of discharge activity for the sloping-up types appear in Figure 11C,D. Across frequency, the $Q$ ratios between control and exposed units are similar. In addition, the results in Figure 11 indicate less of a difference in tuning and frequency selectivity between groups in the sloping-up compared to the saturating RI type.

For criterion frequencies in the middle of the tectorial membrane defect (Fig. 1), the STCs of saturating or sloping-up RI types exhibit complex differences between control and exposed units. Activity at the criterion frequency for saturating RI types showed similar increases with intensity between control and exposed units. However, the STC shape of exposed saturating units was more broadly tuned than in controls. With sloping-up RI types, the reverse was found. Frequency selectivities $(Q)$ in exposed and control sloping-up units were similar, but the rate- 

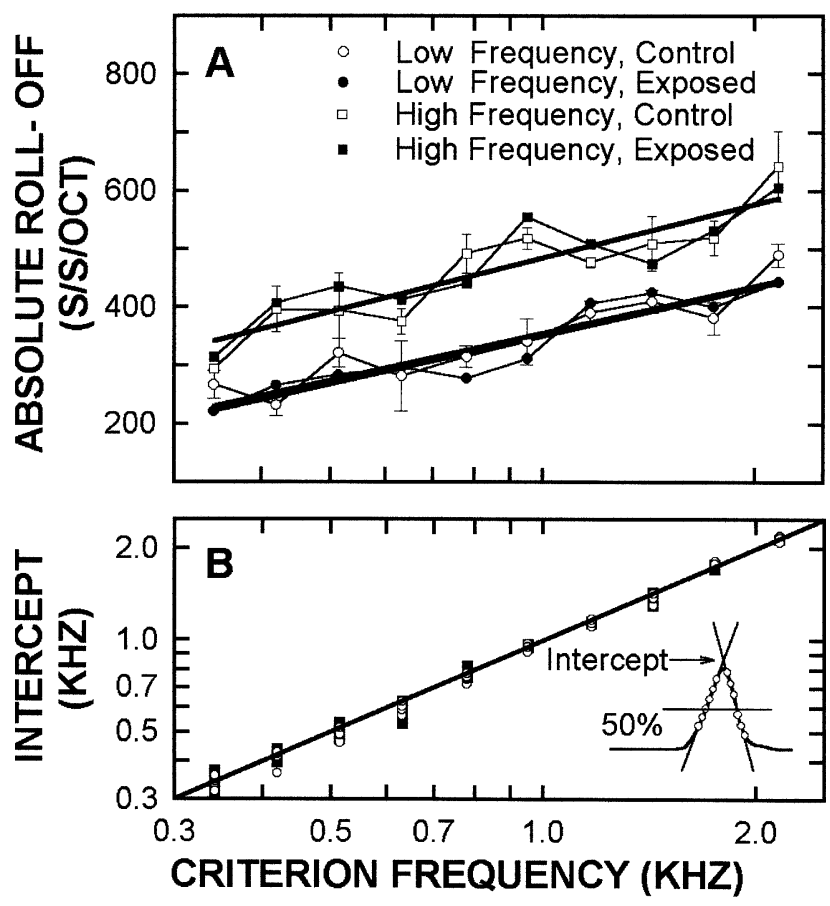

FIG. 9. The slope on the low- and high-frequency skirts in $\mathrm{S} / \mathrm{s} /$ octave (A) are shown for both control and exposed units over all criterion frequencies. The intercept of the low- and high-frequency slopes at all criterion frequencies and levels is shown for both groups (B). The insert demonstrates graphically how slope was calculated.

level function of exposed units grew at a steeper rate and exhibited larger responses at the highest intensities. Above or below the $0.95-\mathrm{kHz}$ criterion frequency, the effects reported in Figures 10 and 11 diminish, and the STCs above 1.17 and below $0.78 \mathrm{kHz}$ were nearly identical between exposed and control curves for both these RI types (data not shown).

\section{DISCUSSION}

\section{Overall considerations}

All chicks examined in our laboratory 12 or 28 days after sound exposure exhibited the same tectorial membrane lesion seen in Figure 1 (Adler and Saunders 1995). This defect may well be a permanent injury in the sound-exposed chick ear.

When organized as isoresponse tuning curves, the spatial distribution of neural activity along the starling basilar papilla correlates with psychophysical tuning curves (Gleich 1994). Simpler procedures were used to construct the present isostimulus contours to evaluate spatial tuning in sound-damaged ears. Despite procedural differences, the spatial distribution of neural excitation exhibited common features between the starling and chick (e.g., in- creasing sharpness as criterion frequency increased, and more broadly tuned functions as intensity increased).

Our results revealed that control and exposed STC shape followed orderly changes with increasing criterion frequency and intensity. These changes are, in part, related to the traveling wave along the avian cochlear partition. Other authors have interpreted the pattern of spatially distributed auditory nerve activity in mammals as an indication of frequency resolution along the length of the organ of Corti (Pfeiffer and Kim 1975; Kim and Molnar 1979; Shofner and Sachs 1986; Kim et al. 1990). If the same interpretation applies to our data, then the patterns of activity reported here are indicative of frequency analysis along the cochlear partition of the chick ear. Nevertheless, the mechanisms of frequency analysis on the chick basilar papilla are less well understood than those in the mammalian cochlea, and this conclusion may be only partially true.

\section{Is the STC a proxy for cochlear mechanics?}

In mammals, auditory nerve frequency selectivity and basilar membrane sharpness of tuning are the same for a common CF (Narayan et al. 1998), implying that neural tuning results from the tuning of the basilar membrane. Moreover, the exquisite properties of frequency selectivity in mammals are attributed to energy applied to the basilar membrane from forces generated by outer hair cell motility (Robles and Ruggero 2001). This motility constitutes a cochlear amplifier that produces nonlinear basilar membrane movements and whose effects are seen in the sharpness of isoresponse tuning curves and in the expanding bandwidths of isostimulus frequency response curves with increasing stimulus intensity (see, e.g., Geisler et al. 1974; Pfeiffer and Kim 1975; Kim and Molnar 1979; Robles and Ruggero 2001). To this must be added the unique properties of the hair cell-auditory nerve synapse. Between 8 and 15 nerve afferent fibers originate from each inner hair cell, and postsynaptic morphology is correlated with neuron spontaneous activity and $\mathrm{CF}$ threshold level (Liberman 1982; Merchan-Perez and Liberman 1996). However, units with a similar CF, but differing in spontaneous activity and threshold level, have tuning curves with the same sharpness (e.g., see Rhode and Smith 1985). Thus, tuning curves with a common CF share a relatively common mechanical input.

Our understanding of basilar membrane motion, its relation to cochlear nerve tuning properties, and the origin of cochlear nonlinearities is relatively poor in the avian ear. Nevertheless, intriguing observations have been published, which lend insight into these 


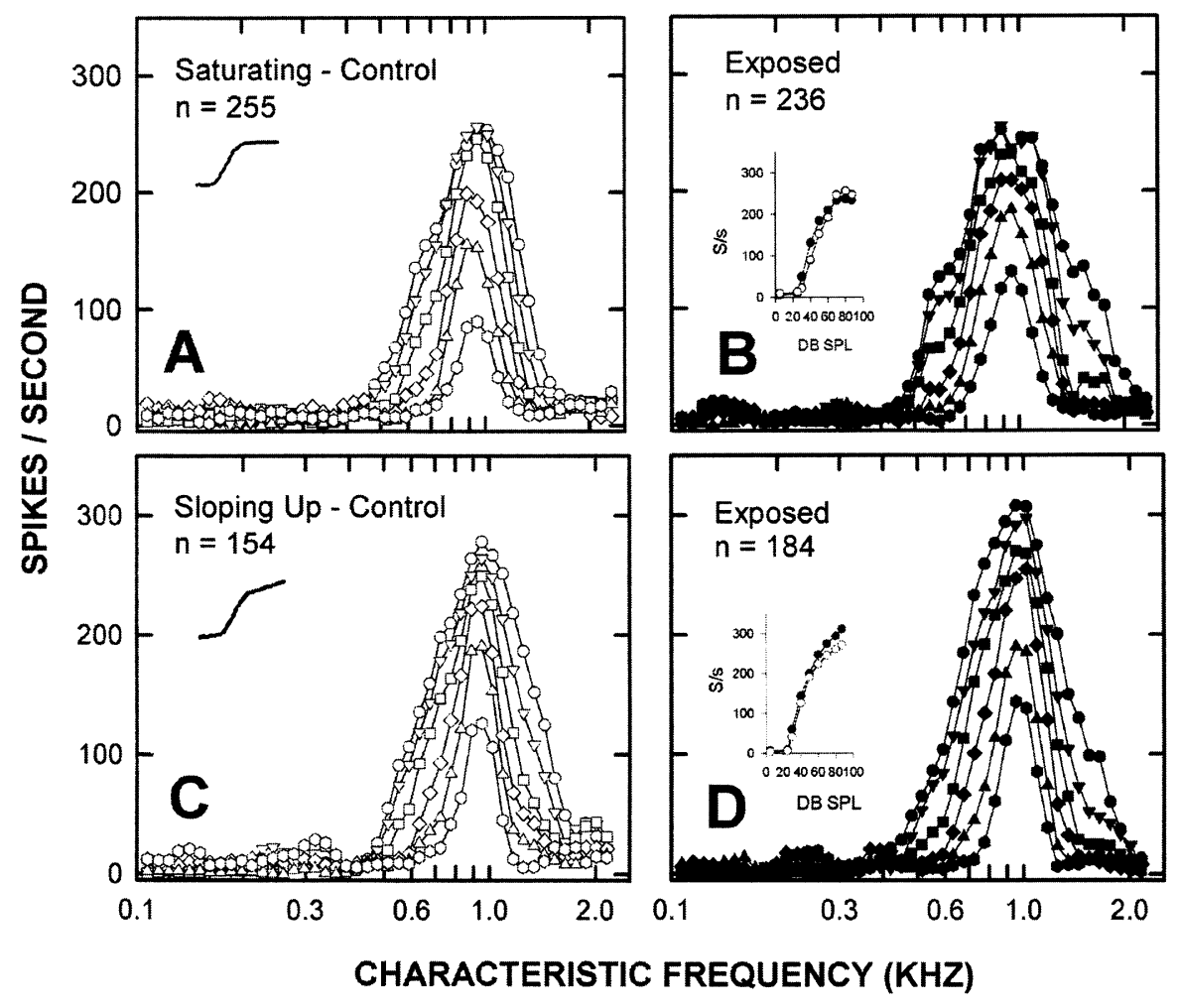

FIG. 10. The STCs of saturating and sloping-up RI units are compared in control $(\mathbf{A}, \mathbf{C})$ and exposed $(\mathbf{B}, \mathbf{D})$ ears at $0.95 \mathrm{kHz}$. The inserts in $\mathbf{A}$ and $\mathbf{C}$ depict the shape of saturating and sloping-up functions, respectively. The inserts in $\mathbf{B}$ and $\mathbf{D}$ show the rate-level activity at the criterion frequency for the respective STCs. Control and exposed symbols represent the following intensities: $(\bigcirc) 87 \mathrm{~dB}$, $(\nabla) 80 \mathrm{~dB},(\square) 70 \mathrm{~dB},(\diamond) 60 \mathrm{~dB},(\Delta) 50$ $\mathrm{dB},(\bigcirc) 40 \mathrm{~dB}$. processes (Köppl and Yates 1999; Yates et al 2000; Saunders et al. 2002).

Avian basilar membrane motion revealed a traveling wave that was broadly tuned (von Békésy 1960; Gummer et al. 1987; Richter 2001), exhibiting highand low-frequency rolloffs comparable to those observed in our STCs. In addition, the growth of basilar membrane movement was directly proportional to sound intensity. The STCs in Figures 3 and 4 are consistent, in part, with these putative descriptions of the avian traveling wave, in that they appear to be broadly tuned with slightly greater selectivity on the high-frequency, compared with the low-frequency, side of the curve. In addition, frequency selectivity increased as criterion frequency increased. The present STCs showed clear evidence of nonlinear behavior in the increasing bandwidth with rising SPL and in spike rate compression at the highest SPLs (Figs. 6 and 7). However, for reasons yet to be identified, nonlinear basilar membrane behavior appeared to be absent in the avian papilla.

Threshold tuning curves in birds, across many units with a common CF, show a three- to fourfold variability in their degree of frequency selectivity from the dullest to sharpest curves (see Manley et al. 1985; Müller and Smolders 1999). For example, the values of $Q_{10 \mathrm{~dB}}$ at $1.0 \mathrm{kHz}$ range between 0.8 and 11.5 in chick (Manley et al. 1991; Saunders et al. 1996). In contrast, the range of $\mathrm{Q}_{10 \mathrm{~dB}}$ values in cat tuning curves at $1.0 \mathrm{kHz}$ is approximately $1.3-3.4$, about a twofold range of variability (Rhode and Smith 1985). The variability in chick frequency selectivity may not be surprising since afferent activity with a common CF arises from multiple hair cells lying along an isofrequency strip between the superior and inferior edges of the papilla. Depending on the orientation of the strip [it may be tilted with regard to the long axis of the papilla (Tilney et al. 1987)], as many as 30-45 hair cells may lie in the $0.95-\mathrm{kHz}$ region, between these edges. Smolders et al. (1995) have shown that tuning curves from labeled neurons in pigeon, originating from hair cells in the inferior portion of the papilla, have high thresholds and broad tuning. Cochlear nerve fibers synapsing on more superior hair cells demonstrate CF thresholds with greater sensitive and frequency selective. Similar results have been reported from labeled cochlear nerve units in the starling (Gleich 1989). Since our sample of units had CF thresholds of $38 \mathrm{~dB}$ SPL or less, they most likely originated from hair cells in more superior papilla locations.

The question remains why it is that units with a common CF exhibit such variance in the frequency selectivity of their tuning curves. There are several possible reasons. The selectivity of mechanical input to the hair bundles might in fact vary across the isofrequency strip, being sharper for some hair bundles and less so for others. Alternatively, there might be a common input to hair bundles along this isofrequency strip, but it is superimposed on intrinsic hair 


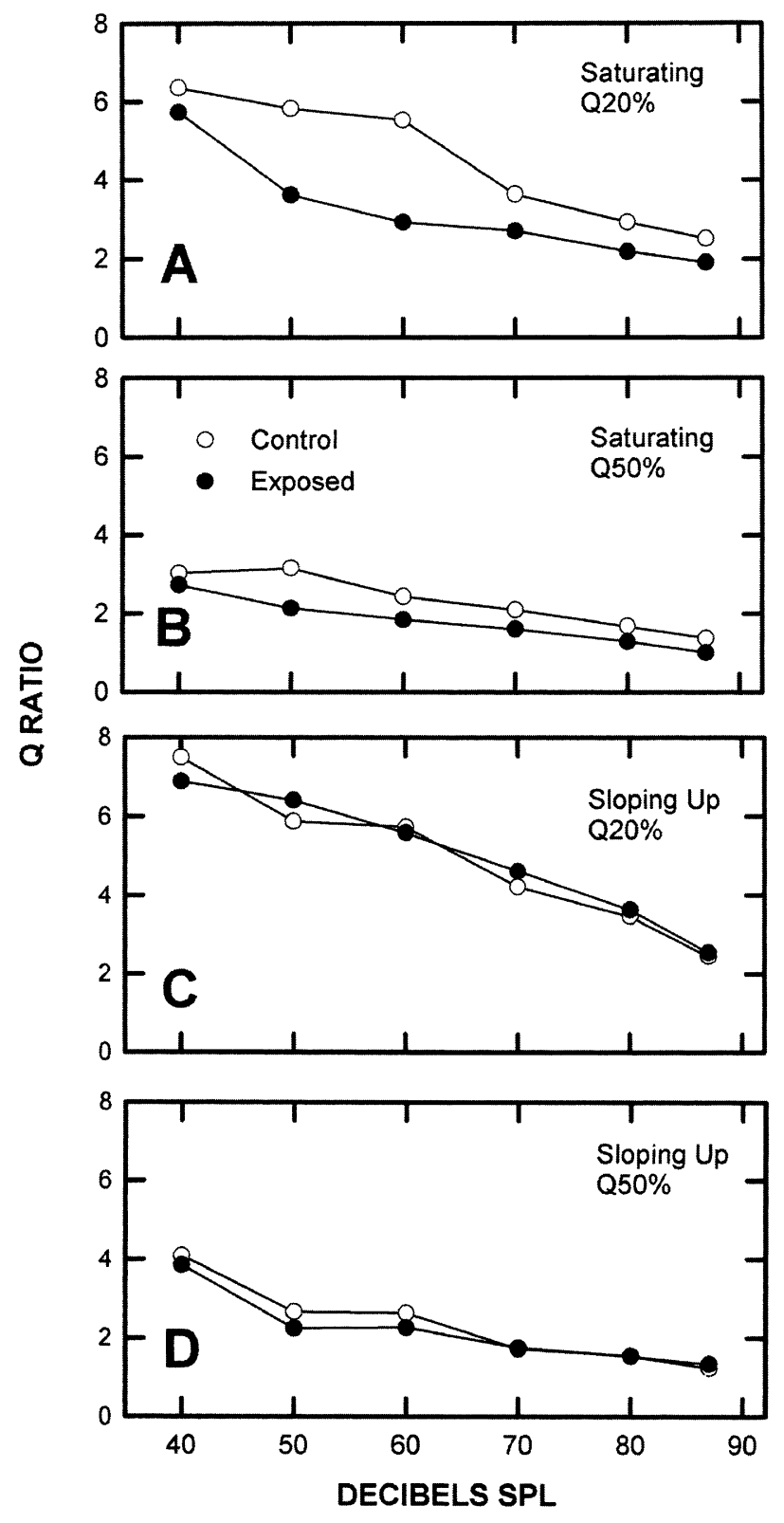

FIG. 11. The shapes of the saturating and sloping-up STCs in Figure 10 are evaluated by examining the $Q$ ratio at each intensity level. The panels distinguish STC shape by RI type and the percent level of the STC at which the ratio was calculated.

cell tuning mechanisms that impart a unique degree of frequency selectivity. Finally, mechanical input and intrinsic hair cell mechanisms might interact in some unique manner. We consider these possibilities below.

The source of mechanical input to the hair cell hair bundles must originate with basilar membrane movement, and this motion, as noted above, may be broadly tuned and linear. A cochlear amplifier like that found in the mammalian cochlea has yet to be identified. In the absence of such an amplifier, it is reasonable to speculate that the mechanical input to chick hair bundles, for those hair cells having a common $\mathrm{CF}$, is much the same, exhibiting the frequency selectivity of basilar membrane tuning. This assumption gains support in recent work demonstrating tip link loss on tall and short hair cells following overstimulation. The loss was similar in both hair cell types suggesting a common mode of hair bundle stimulation (Kurian et al. 2003). Basilar membrane tuning in the bird may be the best or only frequency-selective mechanical signal input to the hair bundle (von Békésy 1960; Gummer et al. 1987; Richter 2001).

Another factor influencing frequency selectivity is electrical tuning of the hair cell membrane. The frequency of electrical tuning in chick hair cells, at different papilla locations, has been reported (Fuchs et al. 1988). Temperature corrections (Schermuly and Klinke 1985), compensating for in vitro to in vivo conditions, yield a reasonable correspondence between papilla location, tonotopic organization, and the frequency to which the hair cell is electrically tuned (Fuchs et al. 1988). When the frequency of electrical tuning matches the frequency of hair bundle motion, then membrane depolarization and neurotransmitter release are greatest. At these conditions, the frequency selectivity seen in cochlear nerve tuning curves represents the combined effects of basilar membrane tuning and electrical tuning. Unfortunately, the sharpness of electrical tuning is unknown in the avian hair cell. Regardless, the effects of a global mechanical input, and a hair-cell-specific tuning mechanism, play an important role in avian frequency analysis. The contribution of each of these mechanisms to papilla frequency selectivity remains to be demonstrated.

It is unclear how compression in the STCs occurred as level increased. Although motility has yet to be found in chick hair cells (Dieler et al. 1994; He et al. 2001; Köppl et al. 2002), and nonlinear behavior may be absent in the basilar membrane response, evidence of nonlinearities in the avian peripheral ear abound. For example, chick tuning curves with a $\mathrm{Q}_{10 \mathrm{~dB}}$ as high as 11 were well beyond that predicted by basilar membrane tuning alone. The effect of nonlinearity also appears in the compressive behavior of avian cochlear nerve rate-intensity functions (Richter et al. 1995; Köppl and Yates 1999; Yates et al. 2000; Saunders et al. 2002). In addition, acoustically or electrically evoked DPOAEs have provided another signature of nonlinear behavior (see, e.g., Köppl 1995; Trautwein et al. 1996; Chen et al. 2001).

The nonlinearity that compressive behavior or distortion products imply must be introduced somewhere between basilar membrane motion and cochlear nerve activity. Moreover, these nonlinearities 
indicated the presence of a cochlear amplifier that most likely enhanced the sharpness of tuning in some cochlear nerve units. It has been proposed that a calcium-dependent motility in sensory hair bundles, at the site of the transduction channel, may be the source of the cochlear amplifier in anuran, reptilian, and avian hair cells (Eguiluz et al. 2000; Martin et al. 2000; Manley 2000; Manley et al. 2001; Hudspeth and Martin 2002). Other possible sources for compressive nonlinearity in the bird ear have recently been suggested (Saunders et al. 2002). These include the multiple neurotransmitter release sites associated with each tall hair cell afferent synapse (MartinezDunst et al. 1997), as well as the curved profile shape of the stereocilia staircase in tall hair cell hair bundles (Duncan et al. 2001).

The processes that determine the shape of the STC in mammals and birds are different. Frequency selectivity and compressive behavior in the responses of the mammalian auditory nerve arise primarily from outer hair cell motility and its influence on basilar membrane mechanics. In the chick ear, the basilar membrane response is broadly tuned, and sharp tuning as well as compressive behavior may be associated with electrical tuning and nonlinear behavior in individual hair cells (Hudspeth and Martin 2002; Manley 2000, 2001; Manley et al. 2001; Martin et al. 2000). The STCs reported here most likely arise from the interplay of global frequency selective processes in the basilar membrane response, interacting with frequency-selective processes occurring in individual hair cells.

The idea that avian cochlear nerve activity comes from a mixture of global (basilar membrane) and local (hair cell) processes has been proposed previously, based on cochlear nerve rate-intensity functions in the owl and emu (Köppl and Yates 1999; Yates et al. 2000). The absence of a common break point in the functions (an observation clearly different from mammals) suggested that local hair cell properties were contributing to the shape of the functions in birds. A similar conclusion was recently reported for chick rate-intensity functions (Saunders et al. 2002). The present data demonstrated the same idea, but now in the frequency domain.

\section{STC shape in control and exposed units}

The results of our study show subtle differences between control and exposed STCs. The local hair cell processes in the regenerated hair cells preserve frequency selectivity in the exposed STCs, implying recovery of electrical tuning. The only observation related to the lesion was the peak response (Figs. 6 and 7 ) which was reliably higher in the exposed group, between 0.78 and $1.17 \mathrm{kHz}$.
Figure 9A reveals that the low- or high-frequency slopes of the STCs were similar in exposed and control ears. However, when segregated by RI type at $0.95 \mathrm{kHz}$, a loss in frequency selectivity and peak response was evident for saturating and sloping-up types, respectively.

\section{CONCLUSIONS}

To help focus future research, we speculate that the STCs result from the interaction of global and localized tuning mechanisms (Köppl and Yates 1999; Yates et al. 2000; Saunders et al. 2002). Global tuning serves to mechanically stimulate hair cell sensory hair bundles. The repaired lower layer of the tectorial membrane in the lesion may be sufficient for this task. The localized tuning originates in individual hair cells and is due to electrical tuning of the hair cell membrane and a compressive nonlinearity that may be associated with mechanisms in the hair bundle. The localized hair cell processes appear to regenerate in exposed ears.

It remains difficult to explain why STC characteristics were unaffected by a major disruption to the tectorial membrane. The most obvious conclusion is that this membrane contributes little or nothing to frequency analysis in the chick ear. The impedance of the basilar membrane may dominate the global input to hair cells, and the tectorial membrane simply serves to communicate those vibrations to the short and tall hair cell bundles. We speculate further that the dominant frequency analytic mechanism resides locally in the hair cells themselves. How true this is remains to be seen.

\section{ACKNOWLEDGMENTS}

This research was supported, in part, by awards from the NIDCD (DC-000710) and the Pennsylvania Lions Hearing Research Foundation to JCS. The authors appreciate the assistance of Ms. Rachel Kurian and Ms. Mary Graham. Critical comments and suggestions from Drs. Thomas Parsons, Michael Anne Gratton, Mark Crumling, and Stephan Wolfe were greatly appreciated. Results in this article were partially presented by Dr. Lifshitz at the 1997 Mid-Winter Meeting of the Association for Research in Otolaryngology (Lifshitz et al. 1997).

\section{REFERENCES}

AdLer HJ, Saunders JC. Hair cell replacement in the avian inner ear following two exposures to intense sound. J. Neurocytol. 24:111-116, 1995.

Chen L, Salvi RJ, Shero M. Cochlear frequency-place map in adult chickens: Intracellular biocytin labeling. Hear. Res. 81:130-136, 1994. 
Chen L, Sun W, SALVI RJ. Electrically evoked otoacoustic emissions from the chicken ear. Hear. Res. 161:54-64, 2001.

Chen L, Trautwein PG, Shero M, Salvi RJ. Tuning, spontaneous activity, and tonotopic map in chicken cochlear ganglion neurons following sound-induced hair cell loss and regeneration. Hear. Res. 98:152-164, 1996b.

Cohen YE, SAunders JC. The effects of sound overexposure on the spectral response patterns of nucleus magnocellularis in the neonatal chick. Exp. Brain Res. 95:202-212, 1995.

Cotanche DA. Regeneration of the tectorial membrane in the chick cochlea following severe acoustic trauma. Hear. Res. 30:197-206, 1987.

Cotanche DA. Structural recovery from sound and aminoglycoside damage in the avian cochlea. Audiol. Neurootol. 4:271-285, 1999.

DelgutTe B. Physiological mechanisms of psychophysical masking: Observations from auditory-nerve fibers. J. Acoust. Soc. Am. 87:791-809, 1990.

Dieler R, Shehata-Dieler WE, Richter CP, Klinke R. Effects of endolymphatic and perilymphatic application of salicylate in the pigeon: II. Fine structure of auditory hair cells. Hear. Res. 74:85-98, 1994.

Duncan RK, Ile KE, Dubin MG, SAunders JC. Hair bundle profiles along the chick basilar papilla. J. Anat. 198:103-116, 2001.

Egulluz VM, Ospeck M, Choe Y, Hudspeth AJ, Magansco MO. Essential nonlinearities in hearing. Phys. Rev. Lett. 84:52325235, 2000.

Fuchs PA, Nagai T, Evans MG. Electrical tuning in hair cells isolated from the chick cochlea. J. Neurosci. 8:2460-2467, 1988.

GeIsLer CD, Rhode WS, KenNedy DT. Responses of tonal stimuli of single auditory nerve fibers and their relationship to basilar membrane motion in the squirrel monkey. J. Neurophysiol. 37:1156-1172, 1974.

GLEICH O. Auditory afferents in starling: Correlation of function and morphology. Hear. Res. 37:255-267, 1989.

GLEICH O. Excitation patterns in the starling cochlea: A population study of primary auditory afferents. J. Acoust. Soc. Am. 95:401409, 1994.

Gummer AW, Smolders JW, Kirnke R. Basilar membrane motion in the pigeon measured with the Mössbauer technique. Hear. Res. 29:63-92, 1987.

He D, Beisel KW, Ding D-L, Chen L, Fritzch B, Salvi RJ. Are chick hair cells mobile? Abstr. Assoc. Res. Otolaryngol. 24:159160, 2001.

Hudspeth AJ, Martin P. Compressive nonlinearity in the hair bundle's active response to mechanical stimulation. Abstr. Assoc. Res. Otolaryngol. 25:3, 2002.

Ipakchi R, SAunders JC. Changes in the cubic difference tone component of the otoacoustic emission in chicks exposed to intense sound. Abstr. Assoc. Res. Otolaryngol. 22:56, 1990.

KIM DO, MOLNAR CE. A population study of cochlear nerve fibers: Comparison of spatial distributions of average-rate and phaselocking measures of response to single tones. J. Neurophysiol. 42:16-30, 1979.

Kim DO, Chang SO, Sirianni JG. A population study of auditorynerve fibers in unanesthetized decerebrate cats: Response to pure tones. J. Acoust. Soc. Am. 87:1648-1655, 1990.

Köppl C. Otoacoustic emissions as an indicator for active cochlear mechanics. A primitive property of vertebrate auditory organs. In: Manley GA, Köppl C, Fastl H, Oeckinghouse H (eds) Advances in Hearing Research. World Scientific, Singapore, pp 207-218, 1995.

Köppl C, YATEs GK. Coding of sound pressure level in the barn owl's auditory nerve. J. Neurosci. 19:9674-9686, 1999.

Köppl C, Forge A, Manley GA, Frost S. No correlation for somatic motility in freeze-fractured hair-cell membranes of lizards and birds. Abstr. Assoc. Res. Otolaryngol. 25:165, 2002.
Kurian R, KRupP NL, SAunders JC. Tip link loss and recovery on chick short hair cells following intense exposure to sound. Hear. Res. 181(1-2): 40-50, 2003.

Liberman MC. Single-neuron labeling in the cat auditory nerve. Science 216:1239-1241, 1982.

Lifshitz J, Altman KW, SAunders JC. Distribution of neural activity along the chick basilar papilla after intense sound exposure. Abstr. Assoc. Res. Otolaryngol. 20:120, 1997.

MANLEY GA. Cochlear mechanisms from a phylogenetic viewpoint. Proc. Natl. Acad. Sci. U.S.A. 97:11736-11743, 2000.

MANLEY GA. Evidence for an active process and cochlear amplifier in non-mammals. J. Neurophysiol. 86:541-549, 2001.

Manley GA, Gleich O, Leppelsack H-J, Oeckinghaus H. Activity patterns of cochlear ganglion neurones in the starling. J. Comp. Physiol. A. 157:161-182, 1985.

Manley GA, Kaiser A, Brix J, Gleich O. Activity patterns of primary auditory-nerve fibers in chickens: Development of fundamental properties. Hear. Res. 57:1-15, 1991.

MANLEY GA, KiRK A, Köppl C, YATEs GK. In vivo evidence for a cochlear amplifier in the hair-cell bundle of lizards. Proc. Natl. Acad. Sci. U.S.A. 97:2826-2831, 2001.

Martin P, Mehta AD, Hudspeth AJ. Negative hair bundle stiffness betrays a mechanism for mechanical amplification by the hair cell. Proc. Natl. Acad. Sci. U.S.A. 97:2026-2031, 2000.

Martinez-Dunst C, Michaels RL, Fuchs PA. Release sites and calcium channels in hair cells of the chick's cochlea. J. Neurosci. 17:9133-9144, 1997.

Merchan-Perez A, Liberman MC. Ultrastructural differences among afferent synapses on cochlear hair cells: Correlations with spontaneous discharge rate. J. Comp. Neurol. 371:208-221, 1996.

Müller M, Smolders JWT. Responses of auditory nerve fibers innervating regenerated hair cells after local applications of gentamycin at the round window of the cochlea in the pigeon. Hear. Res. 131:153-169, 1999.

Narayan SS, Temchin AN, Ruggereo MA. Frequency tuning of basilar membrane and auditory nerve fibers in the same cochleae. Science 282:1882-1884, 1998.

Pfeiffer RR, Kim DO. Cochlear nerve fiber responses: Distribution along the cochlear partition. J. Acoust. Soc. Am. 58:867-869, 1975.

Plontke SK-R, Lifshitz J, Saunders JC. Rate-intensity coding in the cochlear nerve of chicks exposed to intense sound. Brain Res. 842:262-274, 1999.

Poje CP, Sewell DA, Saunders JC. The effects of exposure to intense sound on the DC endocochlear potential in the chick. Hear. Res. 82:197-204, 1995.

Rhode WS, Sмith PH. Characteristics of tone-pip response patterns in relationship to spontaneous rate in cat auditory nerve fibers. Hear. Res. 18:159-168, 1985.

Richter CP. Basilar membrane vibrations measured in the chick papilla basilaris. Abstr. Assoc. Res. Otolaryngol. 24:157, 2001.

Richter CP, HeYnert S, KLinke R. Rate-intensity functions of pigeon auditory primary afferents. Hear. Res. 83:19-25, 1995.

Robles L, Ruggero MA. Mechanics of the mammalian cochlea. Physiol. Rev. 81:1305-1352, 2001.

Saunders JC, Doan DE, Poje CP, Fisher KA. Cochlear nerve activity after intense sound exposure in neonatal chicks. J. Neurophysiol. 76:770-787, 1996.

Saunders JC, Ventetuolo CE, Plontke SK-R, Weiss BA. Coding of sound intensity in the chick cochlear nerve. J. Neurophysiol. 88:2887-2898, 2002.

Schermuly L, Klinke R. Change of characteristic frequency of pigeon primary auditory afferents with temperature. J. Comp. Physiol. 156:209-211, 1985.

SHofner WP, SACHS MB. Representation of a low-frequency tone in the discharge rate of populations of auditory nerve fibers. Hear. Res. 21:91-95, 1986. 
SMOLDERS JW. Functional recovery in the avian ear after hair cell regeneration. Audiol. Neurootol. 4:286-302, 1999.

Smolders JW, Klinke R. Synchronized responses of primary auditory fiber-population in Caiman crocodilus (L.) to single tones and clicks. Hear. Res. 24:89-103, 1986.

Smolders JWT, Ding-Pfenningdorf D, Kuinke R. A functional map of the pigeon basilar papilla: Correlation of the properties of single auditory nerve fibers and their peripheral origin. Hear. Res. 92:151-169, 1995.

Tilney LG, Tilney MS, DeRosier DJ. The distribution of hair cell bundle lengths and orientations suggests an unexplained pat- tern of hair cell stimulation in the chick cochlea. Hear. Res. 24:141-151, 1987.

Trautwein P, Salvi RJ, Miller K, Shero M, Hashino E. Incomplete recovery of chicken distortion product otoacoustic emissions following acoustic overstimulation. Audiol. Neurootol. 1:86103, 1996.

vON BÉKÉsY G. Experiments in Hearing McGraw-Hill, New York, 1960.

Yates GK, Manley GA, Köppl C. Rate-intensity functions in the emu auditory nerve. J. Acoust. Soc. Am. 107:2143-2154, 2000 . 